\title{
THE EFFECT OF EYE DOMINANCE IN COLOR PERCEPTION AMONG DENTAL STUDENTS WITH NORMAL COLOR VISION IN ALEXANDRIA UNIVERSITY
}

\author{
Heba F. Elghorab ${ }^{1 *} B D S$, Ihab A. Hammad 2 PhD, Amir S. Azer 2 PhD, Mohamed A. Nassif 3 PhD
}

\begin{abstract}
INTRODUCTION: Various factors were reported to be responsible for influencing color perception during shade matching. These factors include lighting conditions and viewer's physiological variables. There is limited information regarding the effect of eye dominance in color perception in the dental literature.

OBJECTIVES: To evaluate the effect of eye dominance in color perception among dental students in Alexandria University with normal color vision using Farnsworth- Munsell 100- hue test and the corresponding software.

MATERIALS AND METHODS: One hundred undergraduate dental students without congenital color deficiency were evaluated using Ishihara plates upon their voluntary participation. Out of these 100 participants, 43 were males and 57 were females. The dominant eye of each participant was determined using Miles test. Color perception evaluation was examined using Farnsworth - Munsell 100 hue test (FM 100 hue test). The data were tabulated and statistically analyzed using the Wilcoxon signed-rank test $(\alpha=0.05)$.

RESULTS: Statistical tests showed significant difference between the dominant eye and non-dominant eye in male participants (P=.031) and no significant difference between the dominant eye and non-dominant eye in female participants $(\mathrm{P}=.691)$.

Conclusions: The dominance of the eye had a significant effect in the color perception in male participants.

KEYWORDS: Color matching, eye dominance, FM 100 hue test.

RUNNING TITLE: The effect of eye dominance in color perception. \footnotetext{
2Professor of Fixed Prosthodontics, Conservative Dentistry Department, Faculty of Dentistry, Alexandria University, Alexandria, Egypt. 3Lecturer of Fixed Prosthodontics, Conservative Dentistry Department, Faculty of Dentistry, Alexandria University, Alexandria, Egypt. 4Lecturer of Ophthalmology, Faculty of Medicine, Faiyum University, Egypt.

* Corresponding Author:

E-mail: heba.fouadelghorab@yahoo.com
}

${ }^{1}$ Resident at Conservative Dentistry Department, Division of fixed prosthodontics, Faculty of Dentistry, Alexandria University, Alexandria, Egypt.
\end{abstract}

\section{INTRODUCTION}

Proper shade matching is one of the most challenging goals in clinical dentistry (1). Many methods are currently used to assess the shade matching. These methods are visual and instrumental measurements (2). Shade matching requires an understanding of color harmony and color variations, whether using visual or instrumental methods (3).

Color is all about light. When light hits an object, the object absorbs some of the light and reflects the rest of it. The wavelengths of reflected light determine what color you see (4). Light is captured by photoreceptors. There are two types of photoreceptors, rods and cones. The rod receptors mediate vision at low illumination level, while the cone receptors mediate vision at daylight levels and are responsible for color perception. The retina has three types of receptors. One receptor is sensitive to long wavelengths of the light (red light), another to medium wavelengths of the light (green light) and the third to short wavelengths of the light (blue light) (5).

Various factors are reported to be responsible for influencing color perception during shade matching. These factors include color blindness, aging, fatigue, nutrition, emotions, medications and binocular difference, which is the perception difference between the right eye and the left eye (6). Eye dominance is the tendency to prefer visual sensations in one eye more than the other eye (7). The images are seen more clearly and larger while seeing with the dominant eye. Moreover, the dominant eye was found to be superior to non-dominant eye in visual acuity and motor functions (8). Thus, identification of dominant eye is very important (9).

The Farnsworth- Munsell 100 hue test (FM-100) was designed to evaluate color discrimination between the right eye and the left eye among persons with normal color vision. The Farnsworth-Munsell 100 hue test consists of four separate boxes. There are a total of 85 movable caps and 2 fixed caps at the beginning and the end of each box (5). The first box contains colors from red to red-orange, while the second box contains colors from yellow to yellow-green, the third box contains colors from green to green-blue, and the last and fourth box contains colors from indigo to indigo-magenta (10).

The clinician administers the (FM-100) test to the patient one box at a time. Caps are arranged in a random order. The patient is asked to re-arrange caps in what he/she perceives to be a natural order, from the first pilot cap to the last in two minutes to five minutes(5). Errors are made whenever caps are misplaced from the correct order. The score for any 
individual cap of the FM-100 test "is the sum of the difference between the number of that cap and the numbers of the caps adjacent to it" minus 2. For example if cap number 50 is wrongly positioned between 55 and 56, then the score of this cap is $(55-50+56-50)-2=9$. If this cap no. 50 had been correctly positioned, then the score of that cap would have been $(50-49+51-50)-2=$ zero. Sum of the error scores of the entire set of caps goes to make the total error score (11). Manual scoring of error scores is extremely time consuming and very tedious. To overcome this, many researchers have developed computer programs which calculate the total error scores (12).

No previous work had been conducted in this point in the dental field. Thus, this study was conducted to evaluate the effect of eye dominance in color perception among dental students. The null hypothesis was that eye dominance would not affect the color perception during shade matching.

\section{MATERIALS AND METHODS}

The materials used in this study were:

- Pseudo-isochromatic Plates. (Ishihara test) (Figure 1)

- Farnsworth- Munsell 100- Hue test.( Figure 2)

Ethical Consideration: Approval was obtained from the committee of Ethics and Protection of Human Subjects and all participants have signed the consent form.

Sample: The study was performed at the Faculty of Dentistry, Alexandria University. One hundred dental students participated in this study. Out of these 100 participants, 43 were males and 57 were females.

\section{Criteria of Sample Selection:}

\section{Inclusion criteria}

- Dental students with age range from 18 to 25 years old.

- Dental students with normal color vision.

\section{Exclusion criteria}

- Dental students with congenital color vision deficiency.(identified by Ishihara plates)

- Dental students with history of ocular surgery, presence of ocular disease such as strabismus, retinal pathology.

- Dental students who would not agree to participate in the test.

Standardization of the room: This present study was carried under the same conditions for all the participants. A quiet room with constant lighting conditions using a uniform artificial light source. The method applied in this study was done to simulate the normal clinical situation.

The procedures were conducted as follows:

\section{Color blindness test by Ishihara plates}

The participants were given 4 seconds to identify the number of each plate of the 10 plates as illustrated in table (1). Participants with congenital color deficiency were excluded.

\section{Dominant eye assessment by Miles test}

Each participant was asked to extend both arms in front of his/her body and place their hands together to make a small triangle [Fig. 3]. With both of their eyes open, each participant was asked to look through the triangle, focus on a specific object (a door knob) about 10 feet $(3 \mathrm{~m}$ ) away and try not to move their hands. Then, each participant was asked to close their eyes alternatively. The dominant eye was the eye viewing the object.

III. Color perception assessment by Farnsworth-Munsell 100-Hue test (The FM100 test)
The FM100 test was prepared on a black background. The clinician administered the test to the participant one box at a time. Caps were arranged in a random order. Each participant was asked to re-arrange the caps in what he/she perceives to be a natural order, from the first fixed cap to the last. Each participant was asked to complete each box in five minutes. After the arrangement of the four boxes was done, the clinician flipped the caps and the data were recorded on a paper and transferred to the corresponding scoring software to calculate the total error scores. The test was first performed using the dominant eye then followed by the non-dominant eye.

\section{Calculating the total error scores}

The clinician entered the data to the FMT scoring software, and the final result was obtained.

\section{Statistical analysis of the data}

Data were fed to the computer and analyzed using IBM SPSS software package version 20.0. Qualitative data were described using number and percent. Quantitative data were described using range (minimum and maximum), mean and standard deviation. The significance of the obtained results was judged at the $5 \%$ level.Wilcoxon Signed Ranks Test was used to compare between the dominant eye score and non-dominant eye score.

\section{RESULTS}

The minimum age of participants in this study was 20, while the maximum age was 22 years old. The mean age was 21.300 with a standard deviation of \pm 0.785 . The total number of participants in this study was 100 . Out of these 100 participants, 43 were males (43\%) and 57 were females (57\%). 63 of them had a right dominant eye while 37 had a left dominant eye.

The results showed that there was no significant difference between the dominant eye and non-dominant eye in all participants $(P=0.054)$, as illustrated in table (2) and figure (4). There was no significant difference between dominant eye and non-dominant in female participants with $(P=0.691)$, but there was significant difference between dominant eye and non-dominant in male participants with $(P=0.031)$, as illustrated in table (3) and figure (5).

Table (1): Explanation of the Ishihara plates.

\begin{tabular}{|c|c|c|c|}
\hline $\begin{array}{c}\text { Number } \\
\text { of the } \\
\text { Plate }\end{array}$ & $\begin{array}{c}\text { Normal person } \\
\text { can view the } \\
\text { number of each } \\
\text { plate as follows }\end{array}$ & $\begin{array}{c}\text { Person with Red- } \\
\text { Green } \\
\text { Deficiencies will } \\
\text { read the numbers } \\
\text { as follows }\end{array}$ & $\begin{array}{c}\text { Person with } \\
\text { Total Color } \\
\text { Blindness }\end{array}$ \\
\hline $\mathbf{1}$ & 12 & 12 & 12 \\
\hline $\mathbf{2}$ & 8 & 3 & $\mathrm{x}$ \\
\hline $\mathbf{3}$ & 6 & 5 & $\mathrm{x}$ \\
\hline $\mathbf{4}$ & 29 & 70 & $\mathrm{x}$ \\
\hline $\mathbf{5}$ & 57 & 35 & $\mathrm{x}$ \\
\hline $\mathbf{6}$ & 5 & 2 & $\mathrm{x}$ \\
\hline $\mathbf{7}$ & 3 & 5 & $\mathrm{x}$ \\
\hline $\mathbf{8}$ & 15 & 17 & $\mathrm{x}$ \\
\hline $\mathbf{9}$ & 74 & 21 & $\mathrm{x}$ \\
\hline $\mathbf{1 0}$ & 2 & $\mathrm{x}$ & \\
\hline
\end{tabular}

The mark $x$ shows that the plate cannot be read. 
Table (2): Showing the mean and standard deviation of the error score between the dominant eye and the non-dominant eye in all participants

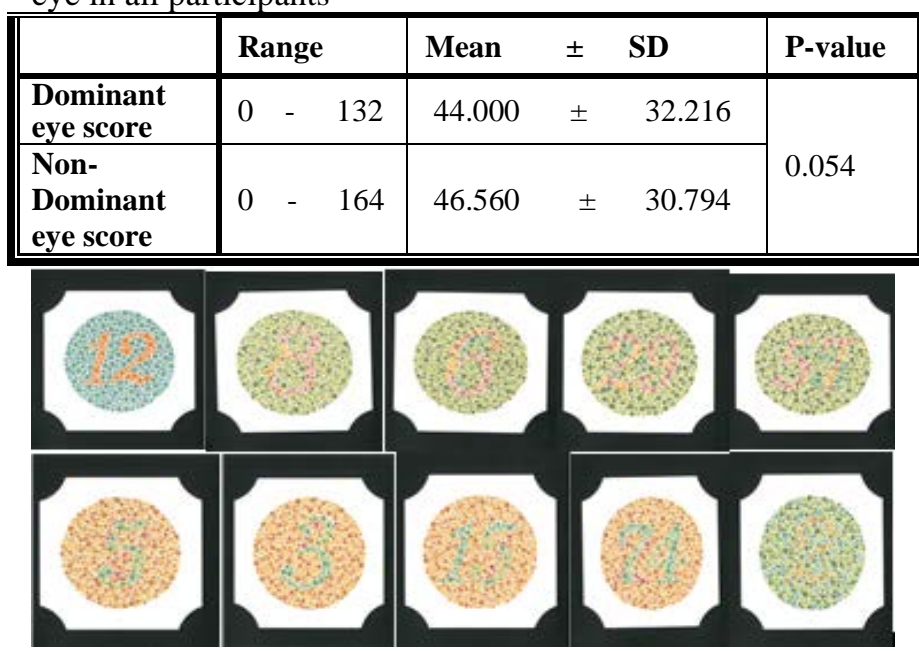

Figure (1): Ishihara plates

Table (3): Showing the mean and standard deviation of the error score between the dominant eye and non-dominant eye in male and female participants.

\begin{tabular}{|c|c|c|c|c|c|}
\hline & \multicolumn{4}{|c|}{ Gender } \\
\hline & & & Male & & emale \\
\hline \multirow{2}{*}{$\begin{array}{l}\text { Dominant } \\
\text { eye score }\end{array}$} & Range & 0 & 120 & $\overline{4}$ & - 132 \\
\hline & $\begin{array}{c}\text { Mean } \\
\pm \text { SD }\end{array}$ & $\begin{array}{c}50.79 \\
1\end{array}$ & $\begin{array}{cc}35.04 \\
\pm \quad 0\end{array}$ & $\begin{array}{c}38.8 \\
77\end{array}$ & \pm 29.187 \\
\hline \multirow{2}{*}{$\begin{array}{c}\text { Non- } \\
\text { Dominant } \\
\text { eye score }\end{array}$} & Range & 0 & 164 & 0 & 124 \\
\hline & $\begin{array}{c}\text { Mean } \\
\pm \text { SD }\end{array}$ & $\begin{array}{c}57.81 \\
4\end{array}$ & $\begin{array}{cc} & 34.76 \\
\pm & 4\end{array}$ & $\begin{array}{c}38.0 \\
70\end{array}$ & \pm 24.483 \\
\hline $\begin{array}{c}\text { Wilcoxon } \\
\text { Signed } \\
\text { Ranks } \\
\text { Test }\end{array}$ & $\begin{array}{c}\text { P- } \\
\text { value }\end{array}$ & & $.031 *$ & & 0.691 \\
\hline
\end{tabular}

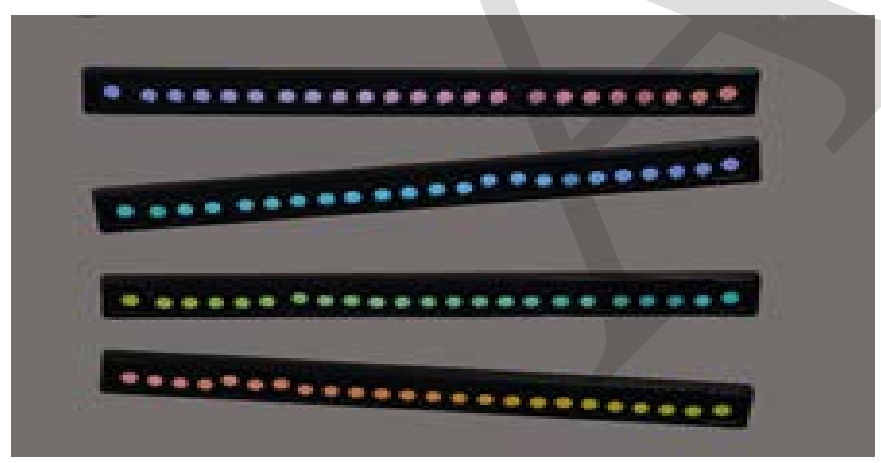

Figure (2) : Farnsworth- Munsell 100- Hue test.

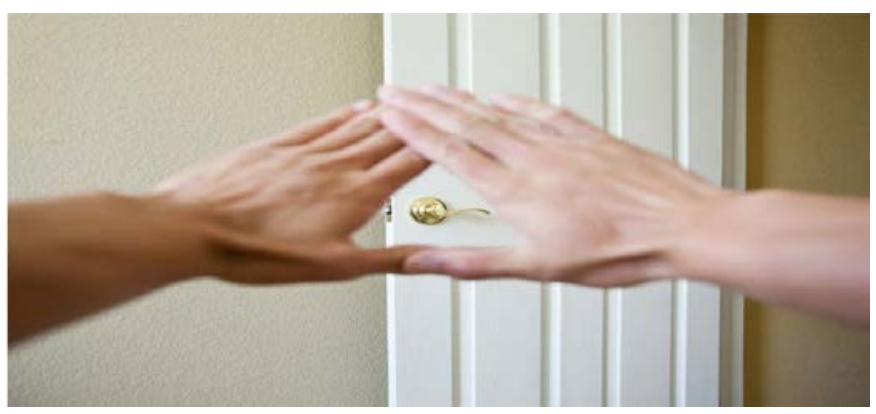

Figure (3): Miles test

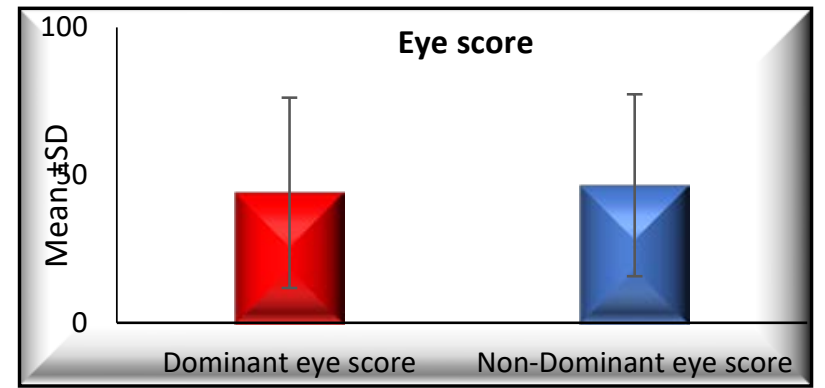

Figure (4): A bar chart Showing the mean and standard deviation of the error score between the dominant eye and the non-dominant eye in all participants.

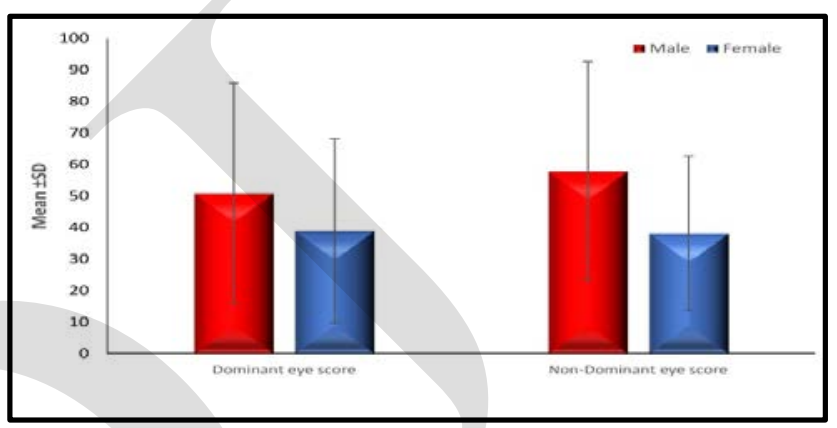

Figure (5): A bar chart showing the mean and standard deviation of the error score between the dominant eye and non-dominant eye in male and female participants.

\section{DISCUSSION}

Proper shade determination continues to be one of the most difficult and frustrating problems in fixed prosthodontics (13). Even though visual shade determination is the most frequently applied method in dentistry (14), the numerous variables involved make it hard for proper shade determination. These variables include lighting conditions and viewer's physiological variables (15).

Color disparity between a person's eyes is crucial and should be accounted for (6).Thus, the present study was conducted to evaluate the effect of eye dominance in color perception using Farnsworth- Munsell 100- hue test and the corresponding software.

It has been established that color perception declines with age because of change in the absorption of light by the ocular media such as the lens, retinal specialized cells (cones), as well as the reduction in pupil size (16).

In order to minimize the aging effect on the eye, dental students belonging to the same age group were chosen to participate in this study. In addition to their similar age range, they have little or no familiarity with color matching. A sample size included 100 undergraduate dental students from Alexandria University with age group range from 18 to 25 years old. A consent form was signed by all the participants.

Ishihara test was used in this study as it is the gold standard for quick diagnosis of congenital color deficiencies (17-19). Farnsworth-Munsell 100-Hue test was used in this study as it was reported to be the most sensitive and reliable test for the determination of the color vision discrimination ability to distinguish colors in detail in healthy subjects $(20,21)$.

Regarding color perception difference between the dominant eye and non-dominant eye in all participants 
$(\mathbf{n}=\mathbf{1 0 0})$, the error scores of the dominant eye were $44.00 \pm 32.22$; while the error scores of the non-dominant eye were $47.40 \pm 30.63$. There was no significant difference between the dominant eye and non-dominant eye in all participants $(P=0.054)$. This was in agreement with of Costa et al (22) who examined 36 students at the Institute of Psychology of the University of São Paulo and found that there were no significant statistical differences between color perceptions measured in the dominant eye, compared with those measured in the non-dominant eye.

Moreover, these findings were similar to those obtained by Opper et al (23) who examine 3 participants and conducted the study at Colorado State University, Department of Psychology, United States and found that eye dominance did not appear to have an effect on color perception.

The result was not in favor with the study of Koçtekin et al (24) who examined 50 students studying at Faculty of Medicine Başkent University, Ankara, Turkey and found that the error scores of the dominant eye were $58.80 \pm 29.92$, while the error scores of the non-dominant eye were $68.44 \pm 31.46$. In all participants, there were significant statistical differences between color perceptions measured in the dominant eye, compared with those measured in the non-dominant eye $(P=0.025)$. This might be due to the decreased sample size they used, as it was 50 participants, while in the present study, it was 100 participants.

Regarding color perception difference between the dominant eye and non-dominant eye in female participants $(\mathbf{n}=\mathbf{5 7})$, the error scores of the dominant eye were $38.877 \pm 29.187$; while the error scores of the nondominant eye were $38.070 \pm 24.48$. There was no significant difference between the dominant eye and non-dominant eye in female participants, $(P=.691)$. This was in agreement with Koçtekin et al (24) who examined 19 female students and found that the error score of the dominant eye in female participants was $51.52 \pm 31.13$, the non-dominant eye was 64.42 $\pm 34.62(P=0.074)$.

Regarding color perception difference between the dominant eye and non-dominant eye in male participants $(n=43)$, ), the error scores of the dominant eye were $50.791 \pm 35.040$; while the error scores of the nondominant eye were $57.814 \pm 34.764$.There was significant difference between the dominant eye and non-dominant eye in male participants, $(P=.031)$. These findings disagreed with Koçtekin et al (24) who examined 31 male students and found that the error score of the dominant eye in male participants was $63.25 \pm 28.76$, the non-dominant eye was $70.90 \pm 29.68(P=0.153)$.

Regarding the effect of eye dominance in color perception during shade matching in males and females, a study tested a large group of dental students and professionals 305 females and 309 males, from different countries under the same color matching conditions and showed females achieved significantly better shade matching results than males (25). It has also been documented that females tend to be better than males at matching colors from memory (26).

Yamamoto (27) stated that because of the possibility of color disparity in the same individual, clinicians should select shades by looking at each patient from the right side of the dental unit and from the left side.
As mentioned before, cones are responsible for color perception. Curcio et al (28) found that cones are concentrated primarily in the center of the retina, and their numbers decline as one moves from the center to the periphery of the retina. The single retina has two halves, usually referred to as nasal (medial) and temporal (lateral) halves. The distribution of cones across the single retina is not uniform; cones are more numerous on the nasal side of the retina than the temporal side. So, under binocular viewing condition, color perception will not be identical for both eyes as stimuli fell upon the nasal retina of one eye and the temporal retina of the other (23).

Altintas et al (29) found that color perception may vary between dominant and non-dominant eyes. Color perception error scores were lower in dominant eyes vs. non-dominant eyes for red/green discrimination. However, eye dominance had no effect on blue/yellow discrimination. Thus, when the subjects were using their dominant eyes, they were better able to perceive red/green color than with their nondominant eyes. Eye dominance displayed no effect on perception of blue/yellow colors.

Koçtekin et al (24) found that the color perception was found prominent for dominant eye. This superiority was attributed to higher sensitivity of the red/green local color spectral region, and concluded that dominant eye has priority in red/green color.

In the present study, in male participants, the error scores of the dominant eye were 50.791 \pm 35.040 ; while the error scores of the non-dominant eye were $57.814 \pm 34.764$. In female participants,the error scores of the dominant eye were $38.877 \pm 29.187$; while the error scores of the nondominant eye were $38.070 \pm 24.48$. According to these results color vision ability of the dominant eye was found higher than non-dominant eye in male participants; while there was no difference in the color vision ability between the dominant eye and non-dominant eye in female participants.

\section{CONCLUSIONS}

The null hypothesis was rejected. Within the limitation of this study, it can be concluded that:

1. The dominance of the eye had a significant effect in the color perception in male participants.

$2.63 \%$ of the participants had a dominant right eye.

3. There was no difference in the color vision ability between the dominant eye and non-dominant eye in female participants.

\section{CONFLICT OF INTERSET}

The authors declare that they have no conflicts of interest.

\section{REFERENCES}

1. Douglas RD, Steinhauer TJ, Wee AG. Intraoral determination of the tolerance of dentists for perceptibility and acceptability of shade mismatch. J Prosthet Dent 2007;97:200-8.

2. Sikri VK. Color: Implications in dentistry. J Conserv Dent 2010;13:249-55.

3. Wee AG, Monaghan P, Johnston WM. Variation in color between intended matched shade and fabricated shade of dental porcelain. J Prosthet Dent 2002;87:657-66. 
4. Brewer JD, Wee A, Seghi R. Advances in color matching. Dent Clin North Am 2004;48:341-58.

5. Melamud A, Hagstrom S, Traboulsi E. Color vision testing. Ophthalmic Genet 2004;25:159-87.

6. Chu SJ, Devigus A, Paravina RD, Mieleszko A. Fundamentals of color: shade matching and communication in esthetic dentistry. $2^{\text {nd }}$ ed. Chicago: Quintessence publications; 2004. p.20-40.

7. Khan AZ, Crawford JD. Ocular dominance reverses as a function of horizontal gaze angle. Vision Res. 2001;41:1743-8.

8. Shneor E, Hochstein S. Eye dominance effects in feature search. Vision Res 2006;46:4258-69.

9. Oishi A, Tobimatsu S, Arakawa K, Taniwaki T, Kira JI. Ocular dominancy in conjugate eye movements at reading distance. Neurosci Res. 2005;52:263-8.

10. Esposito T. An adjusted error score calculation for the Farnsworth-Munsell 100 hue test. Leukos. 2019;15:195-202.

11. Ghose S, Shrey D, Venkatesh P, Parmar T, Sharma S. A simple modification of the Farnsworth-Munsell 100Hue test for much faster assessment of color vision. Indian J Ophthalmol 2014;62:721-3.

12. Hidajat RR, Hidayat JR, McLay JL, Elder MJ, Goode $\mathrm{DH}$, Pointon RC. A fast system for reporting the Farnsworth-Munsell 100-hue colour vision test. Doc Ophthalmol 2004;109:109-14.

13. Sorensen JA, Torres TJ. Improved color matching of metal-ceramic restorations. Part I: A systematic method for shade determination. J Prosthet Dent. 1987;58:133-9.

14. Van der Burgt TP, Ten Bosch JJ, Borsboom PCF, Kortsmit WJ. A comparison of new and conventional methods for quantification of tooth color. J Prosthet Dent. 1990;63:155-62.

15. Carsten DL. Successful shade matching - what does it take? Compend Contin Educ Dent. 2003;24:175-8.

16. Aston ST, Maino JH. Clinical geriatric eye care. Boston: Butterworth-Heinemann; 1993.
17. Birch J. Efficiency of the Ishihara test for identifying red-green colour deficiency. Ophthalmic Physiol Opt. 1997;17:403-8.

18. Lee DY, Honson M. Chromatic variation of Ishihara Diagnostic plates. Color Res Appl. 2003;28:267-76.

19. Dain SJ. Clinical Colour vision tests. Clin Exp Optom. 2004;87:276-93.

20. Kinnear PR, Sahraie A. New Farnsworth-Munsell 100 hue test norms of normal observers for each year of age 5-22 and for age decades 30-70. Br J Ophthalmol. 2002;86:1408-11.

21. Hovis JK, Ramaswamy S, Anderson M. Repeatability indices for the Farnsworth D-15 test. Vis Neurosci. 2005;13:119-23.

22. Costa MF, Ventura DF, Perazzolo F, Murakoshi M. Absence of binocular summation, eye dominance, and learning effects in color discrimination. Vis Neurosci. 2006;23:461-9.

23. Opper JK, Volbrecht VJ. Binocular vs. monocular hue perception. Vision Res. 2017;131:1-15.

24. Koçtekin B, Gündogan NÜ, Alıtntaş AGK, Yazıcı AC. Relation of eye dominancy with color vision discrimination performance ability in normal subjects. Int J Ophalmol. 2013;6:733-8.

25. Haddad HJ, et al. Does gender and experience influence shade matching quality? J. Dent, 2009; 37: 40-4.

26. Pérez-Carpinell J, Baldoví R, de Fez MD, Castro J.Color memory matching:

time effect and other factors. Color Res Appl,1998; 23:234-47.

27. Yamamoto M. Metal-ceramics: principles and methods of makato Yamamoto. Chicago: Quintessence; 1985. p. 232-57

28. Curcio CA, Allen KA. Topography of ganglion cells in human retina. J Comp Neurol 1990;300:5-25.

29. Altintas AK, Gundogan NU, Koctekin BS. The relationship between color vision discrimination ability and depth perception among university students. Int Eye 